\title{
Azithromycin $1.5 \%$ ophthalmic solution: efficacy and treatment modalities in chronic blepharitis
}

\author{
Solução oftálmica de azitromicina 1,5\%: eficácia e modalidades de tratamento em blefarite crônica
}

Ali Fadlallah ${ }^{1}$, Hala El Rami $^{1}$, Dadud Fahd ${ }^{2}$, Ibrahim Dunia ${ }^{2,3}$, Riad Bejuani ${ }^{1,2,3}$, Elie Chlela ${ }^{1}$, Naji Waked ${ }^{1}$, Elyse Jabbour ${ }^{1}$, Sharbel Fahed ${ }^{2,3}$

\section{ABSTRACT}

Purpose: To assess the efficacy of topical 1.5\% azithromycin in the treatment of moderate to severe chronic blepharitis and to compare the efficacy of two different treatment modalities.

Methods: A randomized clinical trial included 67 patients with chronic anterior and/or posterior blepharitis, followed-up for 3 months. Signs and symptoms were graded according to severity. Patients were randomized into two groups: 33 patients in group I and 34 patients in group II. Group I patients were treated with topical $1.5 \%$ azithromycin twice a day for three days, and Group II patients were treated with topical 1.5\% azithromycin twice a day for three days then at bedtime for the rest of the month. All patients were instructed to apply warm compresses and an eye-friendly soap twice daily.

Results: Patients in both groups tolerated the treatment with minimal irritation. A significant improvement in signs and symptoms was noted at the one week follow-up visit. Group II showed a more pronounced and longer-lasting improvement that persisted after three months of follow-up.

Conclusion: Topical 1.5\% azithromycin ophthalmic solution is an effective treatment option for chronic blepharitis. In moderate to severe blepharitis, a one month treatment is safe and shows better improvement than the three-day protocol with no significant relapse until three months of follow-up.

Keywords: Azithromycin/administration \& dosage; Blepharitis/drug therapy; Chronic disease; Ophthalmic solutions; Meibomian glands

\section{RESUMO}

Objetivo: Avaliar a eficácia do uso tópico de azitromicina 1,5\% no tratamento de blefarite crônica moderada a grave, comparando a eficácia de duas diferentes modalidades de tratamento.

Métodos: Um ensaio clínico randomizado incluiu 67 pacientes com blefarite anterior elou posterior crônica, acompanhados por três meses. Os sinais e sintomas foram classificados de acordo com a gravidade. Os pacientes foram randomizados em dois grupos: 33 pacientes no grupo le 34 pacientes no grupo II. Os pacientes do grupo I foram tratados com azitromicina tópica 1,5\% duas vezes ao dia durante três dias, e os pacientes do grupo II foram tratados com azitromicina tópica 1,5\% duas vezes ao dia durante três dias e, em seguida, ao deitar, durante o resto do mês. Todos os pacientes foram instruídos a aplicarem compressas quentes e higiene palpebral duas vezes ao dia.

Resultados: Os pacientes em ambos os grupos toleraram o tratamento com irritação mínima. Melhorasignificativa dos sinais esintomas foiobservada na visita de umasemana de acompanhamento. Grupo Il mostrou uma melhora mais acentuada e mais duradoura que persistiu após três meses de acompanhamento.

Conclusões: A solução de azitromicina oftálmica tópica 1,5\% é uma opção eficaz de tratamento para a blefarite crônica. Em blefarite moderada a grave, o tratamento de um mês é seguro e demonstrou melhora acentuada em relação ao protocolo de três dias, sem recidiva significante até três meses de acompanhamento.

Descritores: Azitromicina/administração \& dosagem; Blefarite/quimioterapia; Doença crônica; Soluções oftálmicas; Glândulas tarsais

\section{INTRODUCTION}

Blepharitis is a common disease of the eyelids. It is characterized by redness, itching, and greasy and crusty eyelashes. Anterior blepharitis affects the anterior lamella of the eyelids, while posterior blepharitis affects the posterior lamella and is due to dysfunction of the meibomian glands with turbid secretions, plugging of the meibomian orifices, and telangiectasia. Blepharitis is typically chronic in nature and is often associated with chalazion, acne rosacea, and dry eyes ${ }^{(1)}$.

Chronic blepharitis appears to be a multifactorial disease, with inflammatory and mechanical components, in addition to a lowgrade infectious component. It is commonly associated with ocular pathogens such as coagulase negative staphylococci, Staphylococcus epidermidis, and Staphylococcus aureus; all of which are normal flora of the eyelid margin ${ }^{(1-4)}$. Due to the relapsing-remitting nature of the disease, the standard treatment regimen is usually for lifetime. It consists of local lid hygiene and eyelid scrubs with warm compresses. Adjunctive treatments include topical antibiotics (usually erythromy- cin or fusidic acid), systemic antibiotics (usually tetracyclines in differing doses), topical corticosteroids, and tear replacement therapy. In severe deformation and scarring, none of the previously mentioned treatment options work. Antibiotics decrease the bacterial load, while corticosteroids relieve the inflammation. However, results are not very satisfying to both patients and physicians, with a low patient compliance and a high recurrence rate after stopping treatment.

Recently, topical azithromycin, a second generation macrolide, has been proposed as a novel treatment, since it appears to be superior to erythromycin ointment and to warm compresses alone in the treatment of blepharitis ${ }^{(5-7)}$. Its advantages reside in a broad-spectrum antibacterial profile, anti-inflammatory properties, a high tissue distribution-particularly in the conjunctiva and eyelids- and an in vivo prolonged post-antibiotic effect ${ }^{(8-12)}$. Its antibacterial activity is directed against many gram-positive and gram-negative bacteria, in addition to atypical bacteria. It binds reversibly to the 505 subunit of the bacterial ribosome and inhibits RNA-dependent protein synthe-
Submitted for publication: November 27, 2011

Accepted for publication: April 3, 2012

Study carried out at the Ophthalmic Consultants of Beirut.

Physician, Department of Ophthalmology, Hotel-Dieu de France Hospital - Ashrafieh, Beirut, Lebanon.

${ }^{2}$ Physician, Ophthalmic Consultants of Beirut Jal-El-Dib, Metn, Lebanon.

${ }^{3}$ Physician, Department of Ophthalmology, Lebanese American University - Hamra, Beirut, Lebanon.
Funding: No specific financial support was available for this study.

Disclosure of potential conflicts of interest: A.Fadlallah, None; H.E. Rami, None; D. Fahd, None; I.Dunia, None; R.Bejjani, None; E.Chlela, None; N.Waked, None; E.Jabbour, None; S.Fahed, None.

Correspondence address: Sharbel Fahed, MD, MS. Ophthalmic Consultants of Beirut - 20/20 Bldg, $1^{\text {st }}$ floor - Jal-El-Dib, Metn, Lebanon - Email: fahd@ocbleb.com 
$\operatorname{sis}^{(13)}$. Azithromycin was studied in bacterial conjunctivitis and proved to be both effective and safe with good patient tolerance ${ }^{(14,15)}$.

The purpose of the present study is to determine the efficacy of topical azithromycin $1.5 \%$ ophthalmic solution combined with eyelid hygiene in the treatment of patients with moderate to severe anterior and/or posterior blepharitis and to compare two different modalities of administration: a three-day regimen versus a prolonged one-month regimen.

\section{METHODS}

A randomized prospective study was performed between July, 2010 and December, 2010 in two different settings: The Ophthalmic Consultants of Beirut, a private practice affiliated with the Lebanese American University, and the Ophthalmology Department of HotelDieu de France Hospital (Saint Joseph University), Beirut, Lebanon. This study was approved by the ethics committee/Investigational Review Board of the Ophthalmic Consultants of Beirut and was carried out in compliance with the Declarations of Helsinki following good clinical practice guidelines.

Sixty-seven patients with diagnosis of moderate to severe anterior and/or posterior chronic blepharitis were enrolled in the study and followed-up for a period of 3 months. Inclusion criteria included patients above the age of 18 years presenting to either the Ophthalmic Consultants of Beirut or the Ophthalmology Department of Hotel-Dieu de France between July, 2010 and December, 2010 with signs of itching, burning, tearing, foreign-body sensation or blurry vision and signs of redness, collarettes, telangiectasia or meibomian gland dysfunction (MGD). Exclusion criteria included refusal of patients to consent for participating in the study, gross lid structural abnormality, and corneal scarring. The aim of the study and the experimental nature of azithromycin in treating blepharitis were explained to all patients. All patients signed an informed consent before participating in the study. Patients were seen and assessed upon diagnosis, and at one week, one month and three months after starting treatment. At each visit, patients were asked about the presence of the following symptoms: itching, burning, tearing, foreign body sensation and blurry vision. The presence of any of these symptoms was graded as specified in table 1. On slit lamp examination, clinical signs of blepharitis were identified. These included: lid collarettes, lid redness and swelling with or without telangiectasia, and MGD consisting of plugging of the meibomian glands (MG) orifices and altered MG secretions. One ophthalmologist examined and graded the signs in all patients. Both eyes of each patient were examined, but only the worse eye of each patient was included in statistical analysis. The same ophthalmologist graded the signs on subsequent visits. This ophthalmologist was blinded to the treatment protocol assigned to each patient but was aware that patients were, or currently are still on treatment.

The scoring system used is outlined in table 1. It was adapted from the International Ocular Inflammation Society (IOIS) grading of signs and symptoms ${ }^{(16)}$ and the grading system of the initial study by Luchs in 2008(6).

Patients were randomly assigned into 2 groups. Randomization was done using a computer-generated number sequence: if the number was even, the patient was assigned to group l; if the number was odd, the patient was assigned to group II. Randomization was not done by the treating physician, but by a third year ophthalmology resident

Exclusion criteria were: lid structural abnormalities, inflammatory or infectious keratitis or iridocyclitis, penetrating intraocular surgery during the past three months, ocular surface surgery (including refractive surgery and pterygiectomy) in the past six months, a known hypersensitivity to azithromycin or any other macrolide antibiotic, and the use of any of the following medications within one month of the study: ocular or oral antibiotics, topical or systemic steroids, ocular nonsteroidal anti-inflammatory drugs, ocular cyclosporine and ocular antihistamine and/or mast cell stabilizers. Pregnant and lactating women were also excluded. Women of childbearing potential were required to use a contraceptive method.

All patients were treated with lid hygiene with an eye-friendly soap at bedtime (Baby Johnson Shampoo, Johnson\&Johnson), and five minutes of warm compresses twice a day. Group I patients were treated with preservative-free, unit-dose, topical 1.5\% azithromycin (Azyter ${ }^{\circledR}$, Laboratoires Thea, France) twice a day for three days, and Group II patients were treated with the same drug, twice a day for three days then once at bedtime for the rest of the month. All groups were instructed to continue warm compresses and lid hygiene for life.

Statistical analysis was done using the Statistical Program for Social Sciences (SPSS) version 13.0 software (SPSS Inc, Chicago, IL, USA). A $p$ value $\leq 0.05$ was considered statistically significant. A Wilcoxon signed rank test (WSR) was used to compare symptoms mean severity score and clinical signs mean severity score variation from baseline and between consecutive visits.

\section{RESULTS}

Seventy Caucasian patients were diagnosed with anterior and/or posterior blepharitis between July, 2010 and December, 2010. Thirty-four patients were assigned to group I, and 36 patients to group II. One patient in group I discontinued prematurely due to allergic reaction, and 2 patients in group II discontinued due to continuous irritation. Consequently, sixty seven patients were treated according to protocol and followed-up for a period of 3 months (33 patients in group I, and 34 patients in group II).

Patients' demographics are presented in table 2 . The study included 32 male patients (48\%) and 35 female patients (52\%). Patients' age varied from 18 to 82 years with a mean of $55.0 \pm 15.1$ years. The two groups were comparable in terms of gender and age ( $p=0.92$ and $p=0.15$, respectively).

Symptoms' mean severity scores at baseline were 2.7 in group I and 2.9 in group II ( $p=0.35)$. The score improved significantly after one

Table 1. Scoring system of signs and symptoms of chronic blepharitis

\begin{tabular}{|c|c|c|c|c|c|}
\hline Scoring & 0 & 1 & 2 & 3 & 4 \\
\hline Symptoms* & Absent & Present some of the time & Present half of the time & Present most of the time & Present all the time \\
\hline Lid collarettes* & Absent & Mild & Moderate & Severe & - \\
\hline Plugging of MG orifices** & $\begin{array}{l}\text { Clear orifices in the middle } \\
\text { part of the lower lid }\end{array}$ & $\begin{array}{l}\text { Plugging }<1 / 3 \\
\text { of orifices }\end{array}$ & $\begin{array}{l}\text { Plugging of } 1 / 3 \text { to } \\
2 / 3 \text { of orifices }\end{array}$ & $\begin{array}{c}\text { Plugging }>2 / 3 \\
\text { of orifices }\end{array}$ & $\begin{array}{l}\text { Plugging of } \\
\text { all orifices }\end{array}$ \\
\hline
\end{tabular}

* = according to the International Ocular Inflammation Society (IOIS) grading of signs and symptoms ${ }^{(16)}$

${ }^{* *}=$ grading system identical to the one used in the 2008 study by Luchs comparing azithromycin to warm compresses ${ }^{(6)}$. The plugging of meibomian glands (MG) orifices score and the MG secretions score were added later on to determine a total meibomian glands dysfunction (MGD) score. This was done for a reporting purpose 
week of treatment to 1.6 and 1.3 respectively ( $p=0.01$ and 0.01 respectively). No further improvement or worsening was noted throughout the three months follow-up period, in both groups (Table 3, with a $p$ value $>0.1$ between all the consecutive visits).

Clinical signs' mean severity scores are depicted in table 4 and in figure 1. Lid collarettes scored 2.2 in group I vs. 2.1 in group II at baseline ( $p=0.67)$. Lid redness/swelling scored 1.3 in group I vs. 1.5 in group II at baseline $(p=0.32)$, and meibomian glands dysfunction (MGD) scored 3.9 in group I vs. 4.1 in group II at baseline $(p=0.36)$.

Concerning lid collarettes, the severity score significantly improved after one week of treatment in both groups with no further change at the one-month and three-months follow-up (with a $p$ value $>0.1$ between all the consecutive visits). Concerning lid redness/ swelling, the severity score significantly improved at one week in both groups, with no further change at the one-month visit (with a $p$ value $>0.1$ between all the consecutive visits). A relapse occurred at three months in group I $(p=0.07)$ while the initial improvement was maintained in group II ( $p=0.01)$. Group II also yielded better results in terms of MGD with a longer-lasting improvement that persisted at the three month' follow-up $(p=0.01)$. Patients in group I had a worsening in MGD at the one-month ( $p=0.06)$ and three-month follow-up visits ( $p=0.11)$. A comparison of the change in clinical signs between both groups is reported in Table 5. At 3 months, patients in group I presented worse results when comparing the score change from baseline in lid redness/swelling ( $p=0.04)$ and MGD $(p=0.03)$.

\section{DISCUSSION}

Chronic blepharitis is a worldwide public health problem due to its prevalence, its chronicity, and the difficulty in treating it. Although no definitive epidemiological data exist in the literature, clinicians agree that its prevalence is very high in the routine ophthalmology consultation. In one study, ophthalmologists and optometrists report a blepharitis rate of $37 \%$ and $47 \%$ respectively in their clinical practice $^{(17)}$

As we previously stated, many treatment options are used to manage this multifactorial resistant disease but none has proved to be curative. Recurrence is very high and lifetime treatments are usually required.

Table 2. Patients' demographics

\begin{tabular}{lccc}
\hline & Group I & Group II & Total \\
\hline $\mathrm{n}(\%)$ & $33(49 \%)$ & $34(51 \%)$ & 67 \\
Males (\%) & $17(52 \%)$ & $15(44 \%)$ & $32(48 \%)$ \\
Females (\%) & $16(48 \%)$ & $19(56 \%)$ & $35(52 \%)$ \\
Mean age \pm SD (years) & $52.0 \pm 14.7$ & $58.0 \pm 15.2$ & $55.0 \pm 15.1$ \\
Age [Min; Max] (years) & {$[18 ; 80]$} & {$[20 ; 82]$} & {$[18 ; 82]$} \\
\hline
\end{tabular}

MGD, the main component of posterior blepharitis, is a chronic, diffuse abnormality of the meibomian glands, commonly characterized by terminal duct obstruction and/or qualitative/quantitative changes in the glandular secretion. This may result in alteration of the tear film, symptoms of eye irritation, clinically apparent inflammation, and ocular surface disease ${ }^{(18)}$.

In this prospective study, we treated all patients with warm compresses and lid hygiene. Adjunctive treatment consisting of 1.5\% azithromycin (Azyter $\left.{ }^{\circledR}\right)$ was used in two different modalities: A three-day protocol (group I) versus a one-month protocol (group II). The study started in summer and stopped before springtime which factors out the effect of pollen - which has also been shown to worsen MGD.

Bias was kept to a minimum by randomization, and by the fact that one blinding ophthalmologist assessed signs unanimously in all patients. This ophthalmologist was also not involved in the direct treatment of these patients.

As expected by randomization, both groups were comparable at the beginning of the study with no statistically significant difference between them in terms of age, gender and all signs and symptoms' severity scores. Both groups had a sustained improvement in symptoms with severity scores significantly better after only one week of starting treatment. The decrease in symptomatology was maintained all the way through the three-month follow-up period with no observed trend toward regression, but this information may be biased considering that patients knew they had received treatment. Concerning clinical signs of blepharitis, significant and rapid improvement occurred at one week in all clinical signs. However, progressive deterioration was observed in group I, with lid redness/swelling and MGD presenting a tendency to recur. Group II showed the best results: improvement in lid redness/swelling and signs of posterior blepharitis (plugging and quality of meibomian glands secretions) was more pronounced and longer-lasting with no trends toward regression at the three-month follow-up visit. All patients strictly adhered to the follow-up schedule that was set. Patients were asked to follow-up as early as one week after starting the treatment to insist on compliance, especially concerning lid hygiene which might be a bothersome maneuver on the long run.

Former studies demonstrated the high efficacy of azithromycin in bacterial conjunctivitis, based on interesting pharmacokinetics that emphasizes its high conjunctival concentration and its prolonged post-administration effect. The azithromycin molecule is extremely lipophilic, a property that makes it more difficult to formulate into an aqueous solution for topical application, but makes its penetration into conjunctival cells easier. In fact, azithromycin incorporates itself into conjunctival cells and has been found in conjunctival biopsies several days after the last drop ${ }^{(8-15)}$

As described previously ${ }^{(8-13)}$, the effect of azithromycin on blepharitis is dual: both antibacterial (antibiotic effect) and anti-inflammatory (by DNA modification). Azithromycin affects neutrophils through mediation of apoptosis, migration, chemotactic activity, and phagocytic function. It is an indirect antioxidant and decreases production of nitric oxide, prostaglandin E2, and proinflammatory cytokines

Table 3. Symptoms' mean severity score with comparisons ( $p$ values) between baseline and each follow-up visit, in addition to $p$ values between follow-up visits

\begin{tabular}{lcccc}
\hline Group & Baseline & $\mathbf{1}$ week & $\mathbf{1 ~ \text { month }}$ & $\mathbf{3}$ months \\
\hline Group I & 2.7 & 1.6 & 1.4 & 1.5 \\
& & $p[1 \mathrm{wk}-$ baseline $]=0.01$ & $p[1 \mathrm{mo}-$ baseline $]=0.01$ & $p[3 \mathrm{mo}-$ baseline $]=0.02$ \\
& & $p[1 \mathrm{mo}-1 \mathrm{wk}]=0.50$ & $p[3 \mathrm{mo}-1 \mathrm{wk}]=0.40$ \\
& & & $p[3 \mathrm{mo}-1 \mathrm{mo}]=0.60$ \\
Group II & 2.9 & 1.3 & 0.9 & 1.3 \\
& & $p[1 \mathrm{wk}-$ baseline $]=0.01$ & $p[1 \mathrm{mo}-$ baseline $]=0.01$ & $p[3 \mathrm{mo}-$ baseline $]=0.01$ \\
& & $p[1 \mathrm{mo}-1 \mathrm{wk}]=0.20$ & $p[3 \mathrm{mo}-1 \mathrm{wk}]=0.80$ \\
& & & $p[3 \mathrm{mo}-1 \mathrm{mo}]=0.10$ \\
\hline
\end{tabular}


Table 4. Clinical signs' mean severity score with comparisons ( $p$ values) between baseline and each follow-up visit

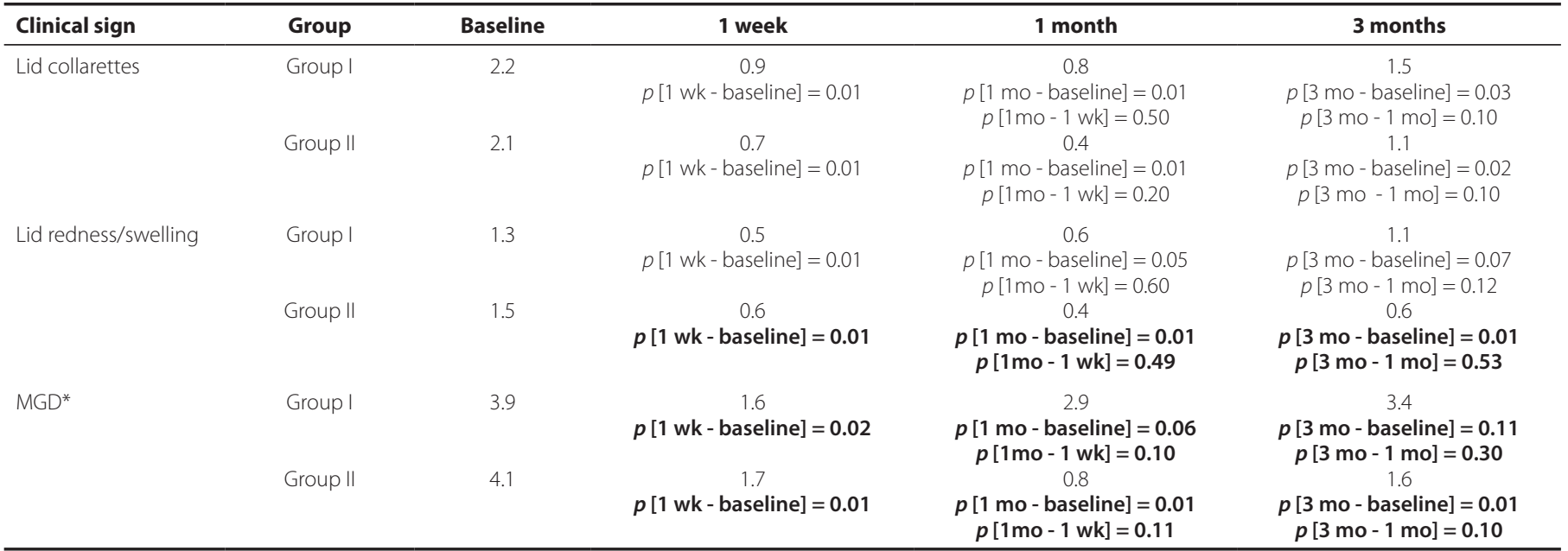

* = total meibomian glands dysfunction (MGD) score. Sum of plugging of meibomian glands (MG) orifices score and the MG secretions score $w k=$ week; $m o=$ month

Table 5. Decrease in clinical signs' mean severity score at the one-week and the one-month follow-up visit with comparisons ( $p$ values) between group I and group II

\begin{tabular}{|c|c|c|c|c|c|}
\hline Clinical sign & Group & Change from baseline to 1 week & $\boldsymbol{p}$ & Change from baseline to 1 month & $p$ \\
\hline Lid collarettes & $\begin{array}{l}\text { Group I } \\
\text { Group II }\end{array}$ & $\begin{array}{l}-1.3 \\
-1.4\end{array}$ & 0.99 & $\begin{array}{l}-1.4 \\
-1.7\end{array}$ & 0.70 \\
\hline Lid redness/swelling & $\begin{array}{l}\text { Group I } \\
\text { Group II }\end{array}$ & $\begin{array}{l}-0.8 \\
-0.9\end{array}$ & 0.82 & $\begin{array}{l}-0.7 \\
-1.1\end{array}$ & 0.04 \\
\hline$M G D^{*}$ & $\begin{array}{l}\text { Group I } \\
\text { Group II }\end{array}$ & $\begin{array}{l}-2.3 \\
-2.4\end{array}$ & 0.45 & $\begin{array}{l}-1.0 \\
-3.3\end{array}$ & 0.03 \\
\hline
\end{tabular}

${ }^{*}=$ total meibomian glands dysfunction (MGD) score. Sum of plugging of meibomian glands (MG) orifices score and the MG secretions score

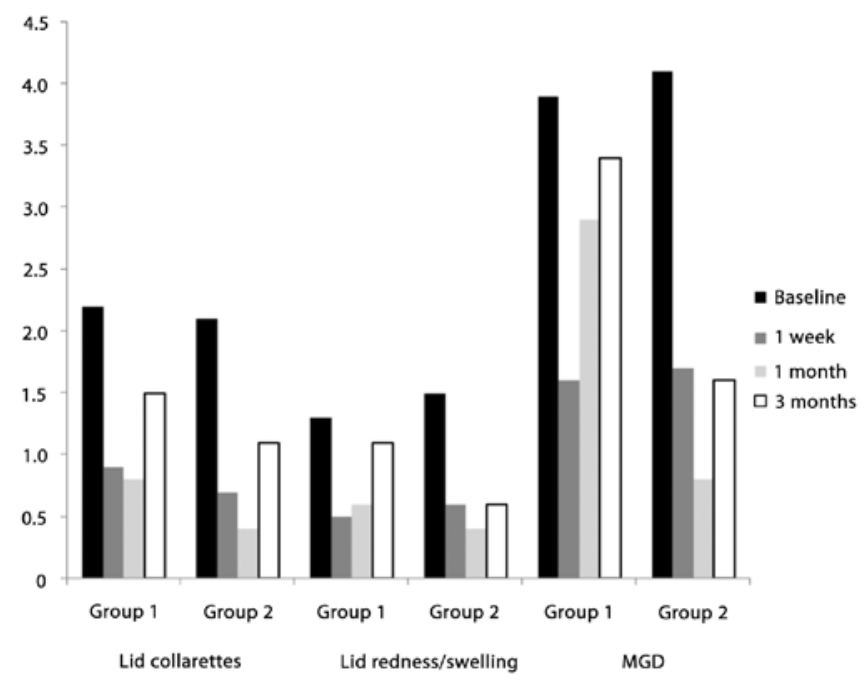

Figure 1. Clinical signs' severity scores in groups 1 and 2 at the different follow-up visits.

interleukin (IL)-8, IL-1 $\alpha$, and tumor necrosis factor (TNF)- $\alpha$. It may also downregulate growth-related oncogene- $\alpha$ and supports the immune system in their attack on mucoid pathogens. To the best of our knowledge, there is no published study assessing the efficacy of Azyter ${ }^{\circledR}$ in blepharitis. Although most of the studies that evaluate azithromycin in blepharitis used AzaSite ${ }^{\circledR}$ (Inspire Pharmaceuticals, Inc, Durham, NC, USA), our results are comparable ${ }^{(8,19-21)}$. AzaSite ${ }^{\circledR}$ is a different formulation of azithromycin with a lower concentration (1\% in AzaSite ${ }^{\circledR}$ vs. $1.5 \%$ in Azyter ${ }^{\circledR}$ ) and a different vehicle for drug delivery that contains benzalkonium chloride.

In Azyter $^{\circledR}$, azithromycin is bound to lipid molecules in solution, thus facilitating its binding to the mucinous and conjunctival cells of the palpebral (and bulbar) conjunctiva ${ }^{(22)}$. Although no polycarbophil drug delivery system is incorporated in Azyter ${ }^{\circledR}$, it achieved satisfactory results in blepharitis in comparison to the studies performed on AzaSite $^{\circledR}$. In the study by Haque et al., treatment with AzaSite ${ }^{\circledR}$ for 28 days (twice a day on days 1 and 2 and once a day on days 3-28) found similar results of significantly improving meibomian gland dysfunction. This lasted at least up to the one-month post-treatment follow-up. Patients were prohibited from using warm compresses in this study ${ }^{(23)}$. Similar results were also found by Opitz and Tyler following a 30-day $1 \%$ azithromycin treatment protocol (twice a day for two days, then every evening for a total of 30 days)(24). Foulks et al. studied the spectroscopic behavior of the meibomian glands' lipids and demonstrated the beneficial effect of topical therapy with $1 \%$ azithromycin on the quality of meibomian glands' secretions. After a one-month treatment with AzaSite ${ }^{\circledR}$ ( 1 drop twice daily for 2 days then once daily) the lipid properties of the meibomian secretions were restored toward normal(25). Thus, an important reason why azithromycin works in blepharitis is because it improves the overall quality of meibum by changing the 50 s ribosomal subunit.

There are no studies comparing AzaSite ${ }^{\circledR}$ to Azyter ${ }^{\circledR}$ concentrations in human ocular tissues. A head to head study comparing the two drugs is needed to see if there is a real difference between the two formulations in terms of efficacy and recurrence rate in the treatment of blepharitis. 
A one month treatment with $1.5 \%$ azithromycin was well tolerated by the patients with minimal irritation. It yielded better results than the three-day protocol recommended by the company for the treatment of bacterial conjunctivitis(22). This is especially true for the posterior signs of the disease with no recurrence at the three months follow-up visit. However, we believe that recurrence will eventually occur because blepharitis is an incurable chronic disease that warrants continuous care. We obviously need a longer follow-up period to assess the exact timing of relapse after this one-month azithromycin regimen. Knowing the extent of the remission period is important for future recommendations, as patients could then take a fixed number of courses per year and be disease-free throughout the whole year.

\section{CONCLUSION}

Azithromycin 1.5\% ophthalmic solution appears to be an effective treatment option for chronic blepharitis. It exerts a beneficial effect on meibomian gland function with an improvement in the quality of lipid secretions.

In moderate to severe blepharitis, a one month treatment with $1.5 \%$ azithromycin (twice daily for three days then once at bedtime for the rest of the month) is safe and well tolerated and resulted in more improvement than a three-day protocol, with a more pronounced and longer-lasting effect on signs of posterior blepharitis

\section{REFERENCES}

1. Huber-Spitzy V, Baumgartner I, Bohler-Sommeregger K, Grabner G. Blepharitis - a diagnostic and therapeutic challenge. A report on 407 consecutive cases. Graefes Arch Clin Exp Ophthalmol.1991;229(3):224-7.

2. Au YK, Jensen HG, Rowsey J, Reynolds M. Coagulase-negative staphylococci in conjunctivitis and blepharitis. Yan Ke Xue Bao. 1993;9(3):129-35.

3. Freidlin J, Acharya N, Lietman TM, Cevallos V, Whitcher JP, Margolis TP. Spectrum of eye disease caused by methicillin-resistant Staphylococcus aureus. Am J Ophthalmol. 2007;144(2):313-5.

4. Oto S, Aydin P, Ciftcioglu N, Dursun D. Slime production by coagulase-negative staphylococci isolated in chronic blepharitis. Eur J Ophthalmol. 1998;8(1):1-3.

5. John T, Shah AA. Use of azithromycin ophthalmic solution in the treatment of chronic mixed anterior blepharitis. Ann Ophthalmol (Skokie). 2008:40(2):68-74.

6. Luchs J. Efficacy of topical azithromycin ophthalmic solution $1 \%$ in the treatment of posterior blepharitis. Adv Ther. 2008;25(9):858-70.

7. Trattler WB KK, Haque R, Zink RC. Topical azithromycin improves blepharitis signs and symptoms. In: Annual Meeting of American Society of Cataract and Refractive Surgery. San Francisco; ASCRS; 3-8 april 2009.
8. Akpek EK, Vittitow J, Verhoeven RS, Brubaker K, Amar T, Powell KD, et al. Ocular surface distribution and pharmacokinetics of a novel ophthalmic 1\% azithromycin formulation. J Ocul Pharmacol Ther. 2009;25(5):433-9.

9. Amar T, Caillaud T, Elena PP. Ocular pharmacokinetic study following single and multiple azithromycin administrations in pigmented rabbits. Curr Eye Res. 2008;33(2): 149-58.

10. Chiambaretta F, Garraffo R, Elena PP, Pouliquen P, Delval L, Rigal D, et al. Tear concentrations of azithromycin following topical administration of a single dose of azithromycin $0.5 \%, 1.0 \%$, and $1.5 \%$ eyedrops (T1225) in healthy volunteers. Eur J Ophthalmol. 2008; 18(1):13-20

11. Torkildsen G, O'Brien TP. Conjunctival tissue pharmacokinetic properties of topica azithromycin $1 \%$ and moxifloxacin $0.5 \%$ ophthalmic solutions: a single-dose, randomized, open-label, active-controlled trial in healthy adult volunteers. Clin Ther. 2008; 30(11):2005-14

12. Wang MG, Zhang YY, Zhu DM, Zhang J, Shi YG. Postantibiotic effects of eleven antimicrobials on five bacteria. Acta Pharmacol Sin. 2001;22(9):804-8.

13. Retsema J, Fu W. Macrolides: structures and microbial targets. Int J Antimicrob Agents 2001;18 Suppl 1:S3-10

14. Abelson MB, Heller W, Shapiro AM, Si E, Hsu P, Bowman LM; AzaSite Clinical Study Group. Clinical cure of bacterial conjunctivitis with azithromycin 1\%: vehicle-controlled, double-masked clinical trial. Am J Ophthalmol. 2008;145(6):959-65.

15. Cochereau I, Meddeb-Ouertani A, Khairallah M, et al. 3-day treatment with azithromycin $1.5 \%$ eye drops versus 7 -day treatment with tobramycin $0.3 \%$ for purulent bacterial conjunctivitis: multicentre, randomised and controlled trial in adults and children. Br J Ophthalmol. 2007;91(4):465-9.

16. BenEzra D. Blepharitis and conjunctivitis. Guidelines for diagnosis and treatment Jerusalem, Israel: Editorial Glosa; 2006

17. Lemp MA, Nichols KK. Blepharitis in the United States 2009: a survey-based perspective on prevalence and treatment. Ocul Surf. 2009;7(Suppl 2):S1-14.

18. Nelson JD, Shimazaki J, Benitez-del-Castillo JM, Craig JP, McCulley JP, Den S, et al. The international workshop on meibomian gland dysfunction: report of the definition and classification subcommittee. Invest Ophthalmol Vis Sci. 2011;52(4):1930-7

19. AzaSite (azithromycin ophthalmic solution). Prescribing information. Inspire Pharmaceuticals, Durham, NC2011.

20. Friedlaender MH, Protzko E. Clinical development of 1\% azithromycin in DuraSite, a topical azalide anti-infective for ocular surface therapy. Clin Ophthalmol. 2007;1 (1):3-10.

21. Crean C, Vittitow, J, Zink, RC. Comparison of Azasite and azithromycin 1\% for bacteria conjunctivitis. In: Annual Meeting of American Society of Cataract and Refractive Surgery. Chicago; ASCRS; 4-9 april 2008.

22. Azyter (azithromycin ophthalmic solution). Prescribing information. Thea laborato ries, Clermont-Ferrand, France, 2010.

23. Haque RM, Torkildsen GL, Brubaker K, Zink RC, Kowalski RP, Mah FS, et al. Multicenter open-label study evaluating the efficacy of azithromycin ophthalmic solution $1 \%$ on the signs and symptoms of subjects with blepharitis. Cornea. 2010;29(8):871-7.

24. Opitz DL, Tyler KF. Efficacy of azithromycin 1\% ophthalmic solution for treatment of ocular surface disease from posterior blepharitis. Clin Exp Optom. 2011;94(2):200-6.

25. Foulks GN, Borchman D, Yappert M, Kim SH, McKay JW. Topical azithromycin therapy for meibomian gland dysfunction: clinical response and lipid alterations. Cornea. 2010:29(7):781-8.

\section{Conselho Brasileiro de Oftalmologia}

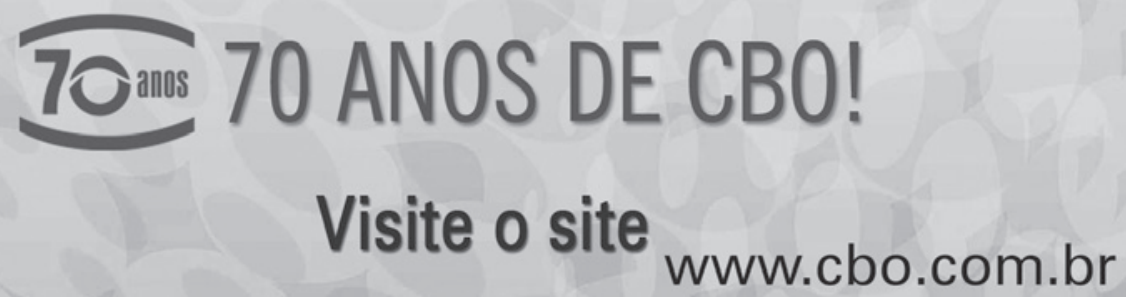

